(2) Open Access Full Text Article

\title{
Pre- and postsynaptic effects of brimonidine on isolated rabbit iris dilator muscles
}

\author{
This article was published in the following Dove Press journal: \\ Clinical Ophthalmology \\ II May 2016 \\ Number of times this article has been viewed
}

\author{
Sonoko Tatsui' \\ Hitoshi Ishikawa ${ }^{2}$ \\ Kimiya Shimizu' \\ Kimiyo Mashimo' \\ 'Department of Ophthalmology, \\ School of Medicine, Kitasato \\ University, ${ }^{2}$ Department of Orthoptics \\ and Visual Sciences, School of Allied \\ Health Sciences, Kitasato University, \\ Sagamihara, Japan
}

Purpose: Brimonidine is an imidazoline compound used for the treatment of glaucoma, but having very little effect on pupil diameter. Like para-aminoclonidine, most imidazoline compounds interact with postsynaptic $\alpha$-adrenoceptors and cause pupil dilatation. Therefore, as part of an investigation of the mechanism of action of brimonidine on pupil diameter, the present study was initiated to measure, in vitro, the relative potency of brimonidine on the pre- and postsynaptic $\alpha$-adrenoceptors of rabbit iris dilator muscle.

Methods: The contractile activity of brimonidine and its effect on twitch contraction evoked by electrical field stimulation were studied in isolated rabbit iris dilator muscles by isometric tension recording.

Results: Brimonidine significantly inhibited the twitch contraction of the dilator muscle caused by field stimulation, without affecting the response to exogenously applied phenylephrine. Compared to phenylephrine, brimonidine caused only a small contractile response with \% maximum contraction values of $<10 \%$.

Conclusion: These results suggest that brimonidine may act on nerve endings to inhibit adrenergic neurotransmission with very little effect on postsynaptic $\alpha$-adrenoceptors. This may indicate that brimonidine reduced the pupil diameter just a little, thus improving night vision.

Keywords: brimonidine, rabbit iris dilator, electrical field stimulation, presynaptic $\alpha_{2}$-adrenoceptor, postsynaptic $\alpha_{1}$-adrenoceptor, imidazolin

\section{Introduction}

Brimonidine and para-aminoclonidine (PAC) are imidazoline compounds and relatively selective alpha ${ }_{2}$-adrenoreceptor agonists. They are used for the treatment of glaucoma and ocular hypertension. ${ }^{1-5}$ Brimonidine and PAC appear to have similar mechanisms of action in their effect on intraocular pressure. Both drugs are known to decrease aqueous production. ${ }^{6-8}$

Mydriasis was frequently noted in eyes treated with $1 \%$ PAC. $^{7}$ Because of this side effect, the use of PAC is limited. Marchini et al ${ }^{9}$ found that brimonidine $0.2 \%$ decreases pupil diameter. McDonald et $\mathrm{al}^{10}$ showed that it causes a significant decrease in pupil diameter only in the dark. In this regard, brimonidine resembles PAC in that both are useful for the treatment of glaucoma, but their effects on pupil diameter are quite different.

The present study was carried out to compare the relative potencies of brimonidine and PAC on pre- and postsynaptic adrenoceptors in the isolated rabbit iris dilator muscle using the isometric tension recording method. Moreover, the mechanism of action of these drugs on pupil diameter will be clarified. 


\section{Materials and methods}

\section{General}

All rabbit procedures were performed in accordance with the Association for Research in Vision and Ophthalmology statement for the Use of Animals in Ophthalmic and Vision Research. All experiments were performed according to the guiding principles for animal experimentation of Kitasato University (approval from the Animal Experiments Ethics Committee, Kitasato University: 2013-185). Male Japanese white rabbits (four albino rabbits) were used. They were purchased at 8 weeks of age and housed in a temperatureand humidity-controlled room $\left(24^{\circ} \mathrm{C}-25^{\circ} \mathrm{C}\right.$ and $55 \%-60 \%$, respectively). Male albino rabbits weighing $2.0-2.5 \mathrm{~kg}$ were killed with an overdose $(60 \mathrm{mg} / \mathrm{kg})$ of intravenous pentobarbital sodium (somnopenty ${ }^{\circledR}$, Schering-Plough Animal Health K.K., Osaka, Japan). The eyes were immediately enucleated and placed in Krebs solution oxygenated with $95 \% \mathrm{O}_{2}$ and $5 \% \mathrm{CO}_{2}$. A dilator muscle specimen ( $2 \mathrm{~mm}$ wide, $4-5 \mathrm{~mm}$ long) was prepared under the microscope (Figure 1) by the method of Kern. ${ }^{11}$ The ends of the specimens were tied with silk thread. Krebs solution with the following composition was used (mM): $\mathrm{NaCl} 94.8, \mathrm{KCl} 4.7, \mathrm{MgSO}_{4} 1.2, \mathrm{CaCl}_{2} 2.5$, $\mathrm{KH}_{2} \mathrm{PO}_{4} 1.2, \mathrm{NaHCO}_{3} 25.0$, and glucose 11.7. All data are expressed as mean \pm standard error of the mean.

\section{Direct contraction experiments}

To measure the isometric development induced by brimonidine, the dilator muscle preparations were mounted vertically in a $10 \mathrm{~mL}$ organ bath containing the oxygenated Krebs solution kept at $37^{\circ} \mathrm{C}$. The preparation was connected to an isometric transducer (EF-601G, Nihon Koden Co., Ltd., Tokyo, Japan) and a hook at the bottom of the organ bath, with initial iris dilator loads of $50 \mathrm{mg}$. The experiment was started after a 60-minute equilibration period. The responsiveness of the preparation was first tested by at least three applications of $1 \mu \mathrm{M}$ phenylephrine (PE) for the dilator, in order to confirm that the same amplitude of contraction would be obtained each time. Brimonidine was administered cumulatively in the bath. The responses were expressed as percentages of the contraction in which $100 \mu \mathrm{M}$ PE-induced contraction was defined as $100 \%$.

\section{Electrical field stimulation experiments}

The muscle preparation was vertically mounted in a $1.5 \mathrm{~mL}$ organ bath and connected to the isometric transducer with an initial load of $50 \mathrm{mg}$. The organ bath was perfused continuously $(0.3 \mathrm{~mL} / \mathrm{sec})$ with the oxygenated Krebs solution at $37^{\circ} \mathrm{C}$. Test drugs were dissolved in this solution in a reservoir. Transmural electrical field stimulation (TEFS) was applied
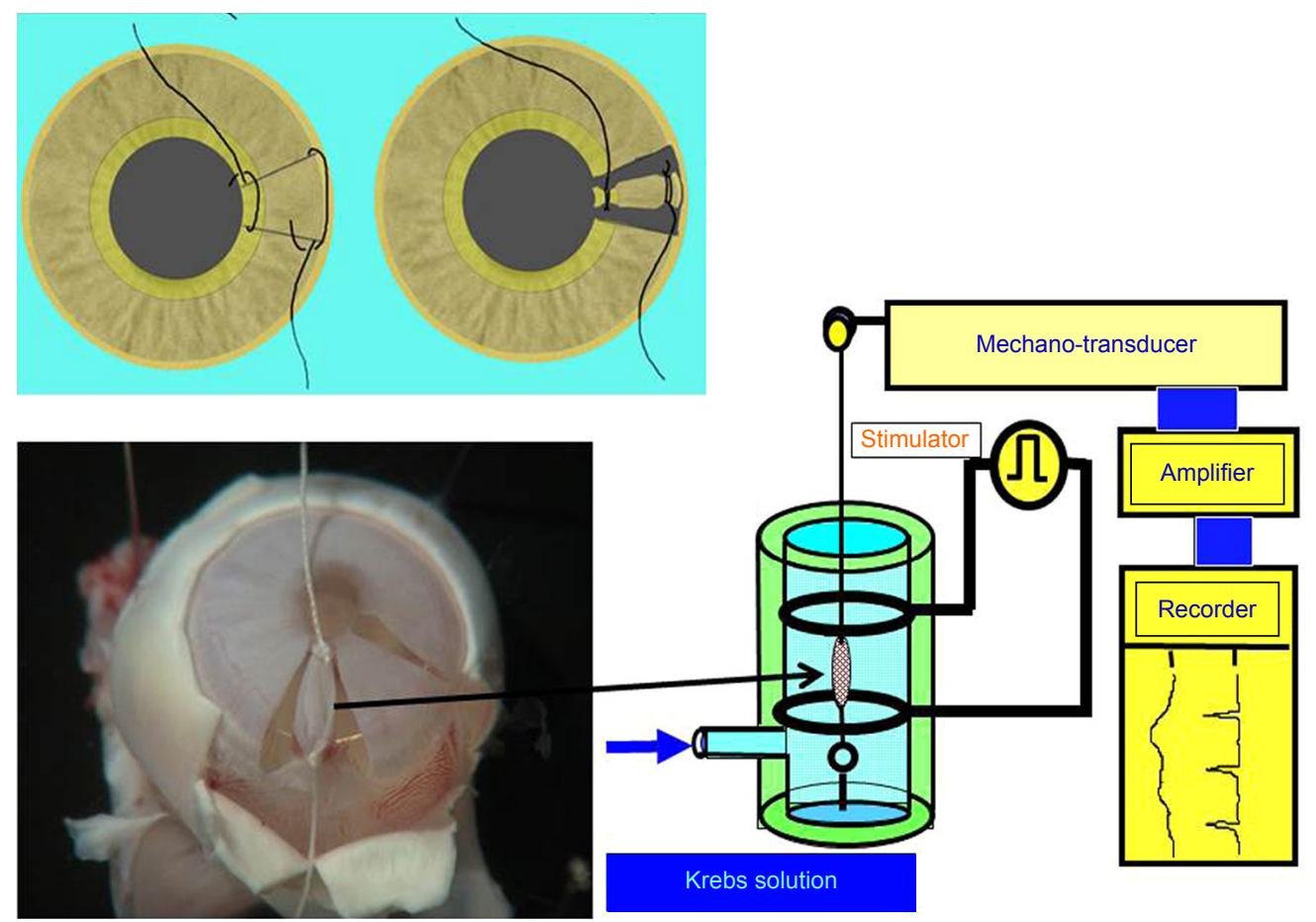

Figure I Muscle preparation.

Notes: The organ bath was perfused continuously with Krebs solution (horizontal blue arrow). 
through a pair of silver-plate electrodes placed in the organ bath. These electrodes were separated by $5 \mathrm{~mm}$ and placed so that the current pulse would pass transversely across the tissue (Figure 1). Seventy pulse stimuli at $20 \mathrm{~Hz}$ were applied using a current pulse of $1.0 \mathrm{~ms}$ in duration and 100 $\mathrm{V}$ in strength. ${ }^{12,13}$ TEFS was applied at intervals of 5 minutes. To obtain constant twitch contractions, the experiment was started after the muscle tone had reached a steady level. Results were expressed as percentages of the control contraction that took place without treatment. When the basal tone of the smooth muscles rose during exposure to higher doses of brimonidine $(>10 \mu \mathrm{M})$, the amplitude of contraction evoked by TEFS or exogenously applied agonists was measured from the elevated baseline to the top of the response.

\section{Chemicals}

The following drugs were used: PE and tetrodotoxin (Wako Pure Chemical Industries Ltd., Osaka, Japan); brimonidine was a generous gift from Senju Pharmaceutical Co., Ltd., Tokyo, Japan. All others were of reagent grade.

\section{Results}

\section{Contractile activity}

Specimens of the rabbit iris dilator muscles, mounted in an organ bath, gradually relaxed to a steady level during a 60-minute equilibrium period, and the muscle tone then remained constant for several hours. Spontaneous mechanical responses did not occur at any time during these procedures. PE dose-dependently induced rapid contractions with half maximal effective concentration $\left(\mathrm{EC}_{50}\right)$ values of $6.7 \pm 1.7 \mu \mathrm{M}$ (Figures 2 and 3). On the dilator tissue of each iris, the concentration-response curve to the reference PE was generated first, and then brimonidine was administered cumulatively. Brimonidine caused very weak contractions with a threshold dose of $10 \mu \mathrm{M}$ (Figure 4).

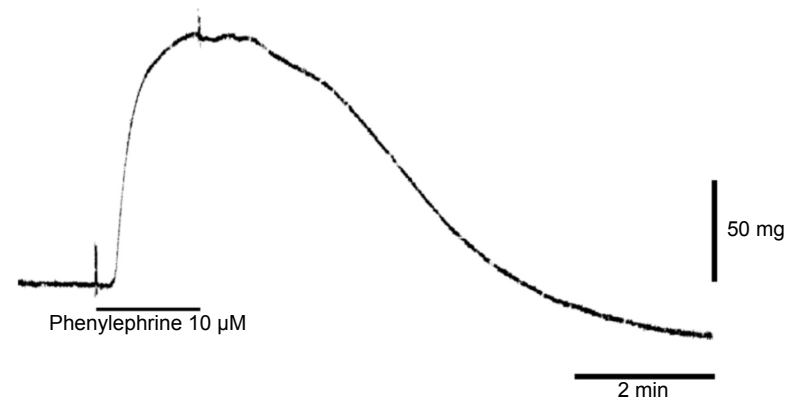

Figure 2 Tracing showing contractile patterns of the iris dilator muscle induced by phenylephrine.

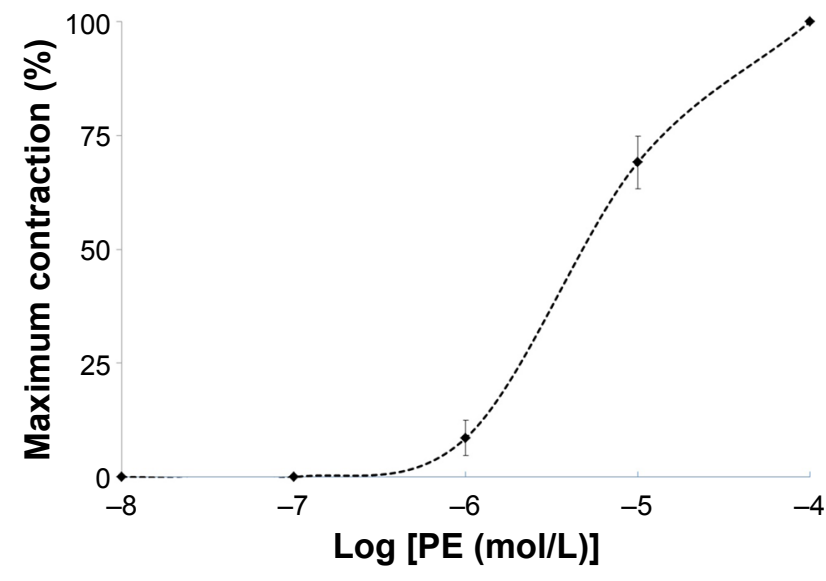

Figure 3 Concentration-response curves in the iris dilator muscles for PE. Note: Each point represents the mean of six experiments, the bars indicating SEM. Abbreviations: PE, phenylephrine; SEM, standard error of the mean.

The $\%$ maximum contraction value for brimonidine was $8.5 \% \pm 4.3 \%$.

\section{Effect on twitch contraction induced by field stimulation}

TEFS caused twitch contraction in the dilator muscles. The twitch contraction was completely blocked by treatment with tetrodotoxin $(0.1 \cdot \mu \mathrm{M})$, indicating that the mechanical response was neurogenic in origin (Figure 5). Brimonidine obviously inhibited the twitch contraction despite the substantial rise of the basal tone of the preparations (Figure 5). In the presence of tetrodotoxin $(0.1 \cdot \mu \mathrm{M})$, exogenously applied PE caused contractions of the iris dilator muscle (Figure 5). Brimonidine, as shown in detail in Figure 6, dose-dependently inhibited the twitch contraction. Brimonidine $(1 \mu \mathrm{M})$ did not affect the dose-response curves of PE (data not shown).

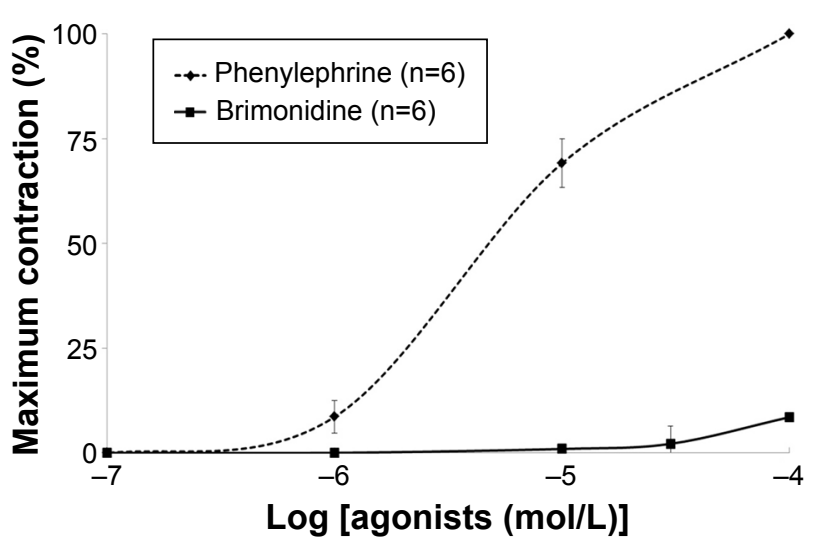

Figure 4 Concentration-response curves of phenylephrine and brimonidine. Note: The $\%$ maximum contraction value of brimonidine is $<10 \%$. 


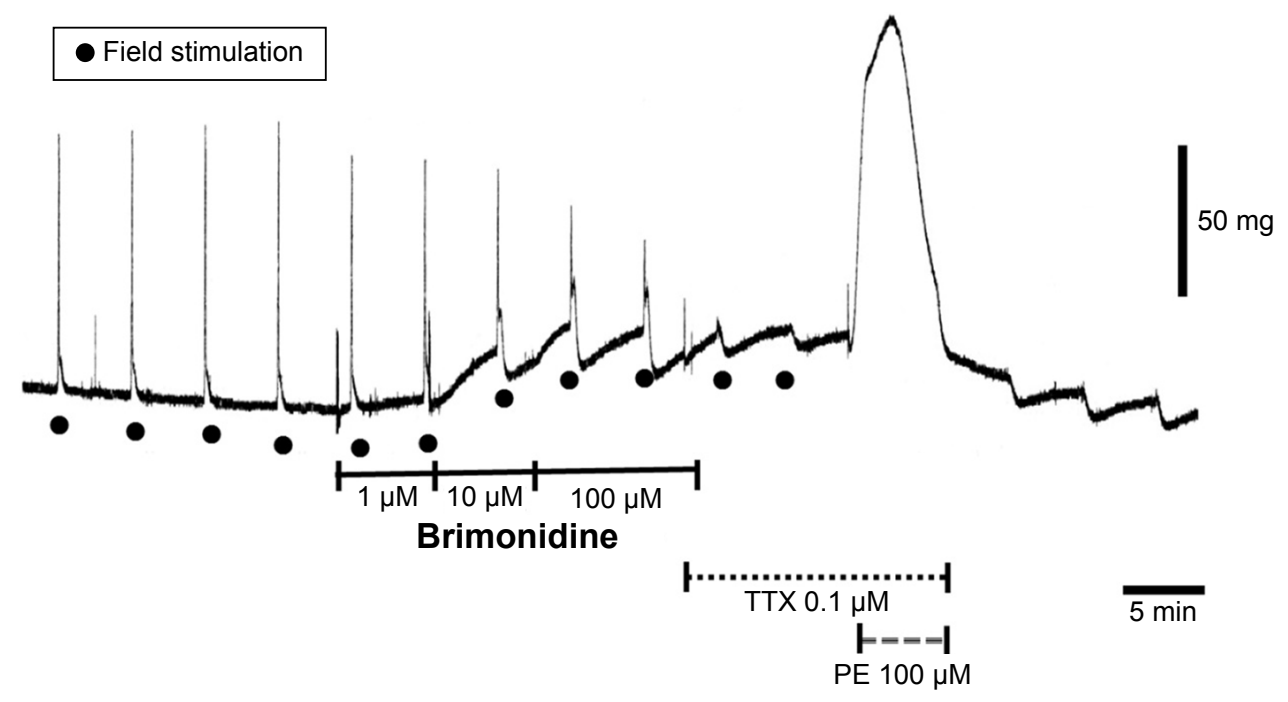

Figure $\mathbf{5}$ Tracings showing twitch contractions induced by field stimulation and contractile responses induced by exogenously applied PE (I00 $\mu \mathrm{M}$ ).

Notes: Brimonidine dose-dependently inhibited the twitch contractions despite the substantial rise of the basal tone. Transmural electrical field stimulation-induced contractions were completely abolished in the presence of TTX, although exogenously applied PE caused contraction.

Abbreviations: PE, phenylephrine; TTX, tetrodotoxin.

\section{Discussion}

Postsynaptic functional $\alpha_{1}$-adrenoceptor is present in the isolated rabbit iris dilator muscle. Alpha-adrenoceptor-mediated effects of agonists in this tissue are well documented. ${ }^{14-16}$ The present results show that brimonidine induced very weak contractions, with a $\%$ maximum contraction value of $<10 \%$, in the isolated rabbit iris dilator muscle. On the other hand, Ishikawa et $\mathrm{a}^{16}$ reported that the $\%$ maximum contraction value of PAC is $51 \%$ in the same tissue using the same method performed by the same examiner. The most likely cause for pupil dilatation induced by PAC is $\alpha_{1}$-adrenoceptor stimulation, similar to that of other partial adrenergic agonists and imidazolines. Generally, imidazoline is an interesting

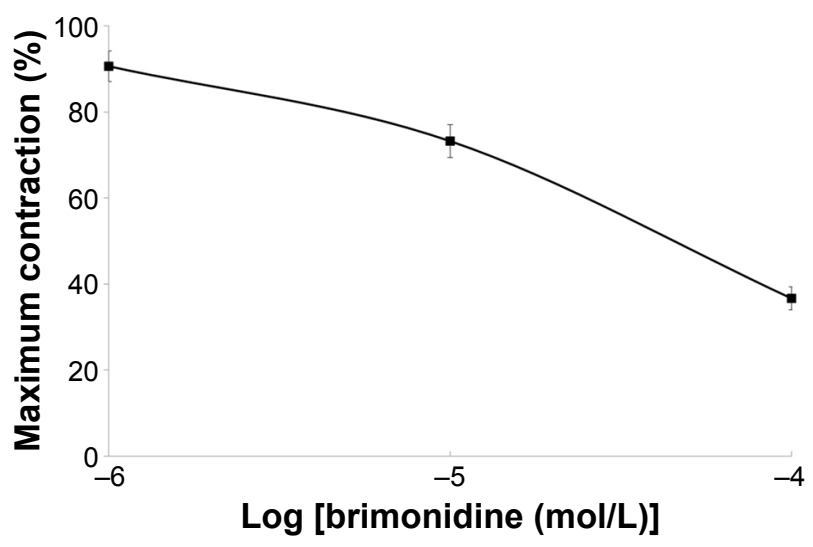

Figure 6 Brimonidine dose-dependently inhibited the transmural electrical field stimulation-induced contractions.

Note: Each point represents the mean of eight experiments, the bars indicating SEM. Abbreviation: SEM, standard error of the mean. class of direct-acting, $\alpha$-adrenoceptor stimulants that are products of the chemistry laboratory. The charged imidazoline ring is believed to react with the $\alpha$-adrenoceptor. In sufficient concentrations, the imidazoline drugs can produce mydriasis, but the low concentration present in topical ophthalmic preparations is unlikely to have such an effect.

Brimonidine is a synthetic imidazoline $\alpha_{2}$-adrenoceptorinteracting drug. PAC is another imidazoline which has been observed to lower intraocular pressure to the same extent as brimonidine. However, the effects of these drugs on the pupil are different.

Our results show that brimonidine dose-dependently inhibited the twitch contraction evoked by TEFS in the dilator muscle. Moreover, brimonidine did not significantly affect the contractile response induced by exogenously applied PE. These results suggest that brimonidine may inhibit norepinephrine release through the $\alpha_{2}$-adrenoceptors located at the adrenergic nerve terminals.

Generally, $\alpha_{2}$-adrenoreceptors are present on the sympathetic nerve ends. When a neurotransmitter and a receptor agonist bind to the same receptor, $\alpha_{2}$-adrenoreceptors act to inhibit the release of norepinephrine by negative feedback. Thus, contractility inhibition occurs in the dilator muscle. Using this effect, brimonidine is useful in reducing night-vision disturbances, such as glare and halos, after refractive surgery. ${ }^{17-21}$

Burke et al examined the effects of $\alpha_{2}$-adrenoreceptor agents in rabbits, and reported that the comparative mydriatic effects were in the order PAC (strong effect) $>>$ clonidine $>$ brimonidine (no effect). ${ }^{17}$ Burke et al also examined 
the affinity of both brimonidine and PAC to $\alpha_{1}$ - and $\alpha_{2}$-adrenoceptors with the human cerebral cortex and the HT-29 human colonic cell line using $\left[{ }^{3} \mathrm{H}\right]$ prazosine and $\left[{ }^{3} \mathrm{H}\right]$ rauwolscine to label as radioligand-binding assays. ${ }^{18}$ In these experiments, brimonidine was reported to be 1,000 times more selective for the $\alpha_{2}$-adrenoceptor than $\alpha_{1}$-adrenoceptors, and 23-32 times more $\alpha_{2}$-selective than PAC. ${ }^{17,18}$

These results taken together suggest that brimonidine in physiological concentrations mainly activates presynaptic $\alpha_{2}$-adrenoceptors and causes a small amount of pupil miosis without affecting postsynaptic $\alpha_{1}$-adrenoceptors. However, in comparison with the PAC, the affinity of brimonidine for postsynaptic $\alpha_{1}$-adrenoceptors is low, and therefore does not cause pupil dilatation.

\section{Conclusion}

We examined the mechanisms of pupil reaction using two different imidazoline classes of $\alpha_{2}$-adrenoceptor stimulators, brimonidine and PAC. Brimonidine is effective not only in lowering intraocular pressure, but also improves the night vision with a small amount of pupil miosis.

\section{Acknowledgment}

The authors thank CWP Reynolds for linguistic advice on this manuscript.

\section{Disclosure}

The authors report no conflicts of interests in this work.

\section{References}

1. Kitazawa Y, Taniguchi T, Sugiyama K. Use of apraclonidine to reduce acute intraocular pressure rise following Q-switched Nd:YAG laser iridotomy. Ophthalmic Surg. 1989;20:49-52.

2. LeBlanc RP. Twelve-month results of an ongoing randomized trial comparing brimonidine tartrate $0.2 \%$ and timolol $0.5 \%$ given twice daily in patients with glaucoma or ocular hypertension. Brimonidine Study Group 2. Ophthalmology. 1998;105:1960-1967.

3. David R, Spaeth GL, Clevenger CE, et al. Brimonidine in the prevention of intraocular pressure elevation following argon laser trabeculoplasty. Arch Ophthalmol. 1993;111:1387-1390.

4. Cheng JW, Cheng SW, Gao LD, Lu GC, Wei RL. Intraocular pressurelowering effects of commonly used fixed-combination drugs with timolol a systematic review and meta-analysis. PLoS One. 2012;7(9):e45079.

Clinical Ophthalmology

\section{Publish your work in this journal}

Clinical Ophthalmology is an international, peer-reviewed journal covering all subspecialties within ophthalmology. Key topics include: Optometry; Visual science; Pharmacology and drug therapy in eye diseases; Basic Sciences; Primary and Secondary eye care; Patient Safety and Quality of Care Improvements. This journal is indexed on
5. Li T, Lindsley K, Rouse B, et al. Comparative effectiveness of first-line medications for primary open-angle glaucoma: A systematic review and network meta-analysis. Ophthalmology. 2016;123(1):129-140.

6. Gharagozloo NZ, Relf SJ, Brubaker RF. Aqueous flow is reduced by the alpha-adrenergic agonist, apraclonidine hydrochloride (ALO 2145). Ophthalmology. 1988;95(9):1217-1220.

7. Robin AL. Short-term effects of unilateral $1 \%$ apraclonidine therapy. Arch Ophthalmol. 1988;106:912-915.

8. Serle JB, Steidl S, Wang RF, et al. Selective $\alpha_{2}$-adrenergic agonists B-HT 920 and UK14304-18: Effects on aqueous humor dynamics in monkeys. Arch Ophthalmol. 1991;109:1158-1162.

9. Marchini G, Babighian S, Tosi R, et al. Effects of $0.2 \%$ brimonidine on ocular anterior structures. J Ocul Pharmacol Ther. 1999;15:337-344.

10. McDonald JE 2nd, El-Moatassem Kotb AM, Decker BB. Effect of brimonidine tartrate ophthalmic solution $0.2 \%$ on pupil size in normal eyes under different luminance conditions. $J$ Cataract Refract Surg. 2001;27:560-564.

11. Kern R. The adrenergic receptors of the intraocular muscles of man. An in vitro-study [Die adrenergischen receptotren der intraocularen muskeln des menschen]. Albrecht Von Graefes Arch Klin Exp Ophthalmol. 1970;180(3):231-248. German.

12. Yoshitomi T, Ito Y. Effects on indometacin and prostaglandins on the dog iris sphincter and dilator muscles. Invest Ophthalmol Vis Sci. 1988;29: $127-132$.

13. Ishikawa $\mathrm{H}$, Yoshitomi $\mathrm{T}$, Harada $\mathrm{Y}$, Katori M, Ishikawa S. The presence of two sites of action of endothelins in the isolated rabbit iris sphincter and dilator muscles. Curr Eye Res. 1993;12(12):1049-1055.

14. Konno F, Takayanagi I. Characterization of postsynaptic alpha1adrenoceptors in the rabbit iris dilator smooth muscle. Naunyu Schmieducberg's Arch Pharmacol. 1986;333:271-276.

15. Takayanagi I, Shiraishi K, Kokubu N. Alpha 1B-adrenoceptor mechanisms in rabbit iris dilator. Jpn J Pharmacol. 1992;59:301-305.

16. Ishikawa H, Miller DD, Patil PN. Comparison of post-junctional alpha-adrenoceptors in iris dilator muscle of humans, and albino and pigmented rabbits. Naunyu Schmiedebergs Arch Pharmacol. 1996;354: 156-772.

17. Burke J, Manilapaz C, Kharlamb A, et al. Therapeutic use of $\alpha_{2}$-adrenoceptor agonists in glaucoma. In: Lanier S, Limbird L, editors. Alpha-adrenergic Receptors Structure Function and Therapeutic Implications. Reading. Harwood Academic Publishers; 1996:179-187.

18. Burke J, Schwartz M. Preclinical evaluation of brimonidine. Surv Ophthalmol. 1996;41:S9-S18.

19. Lee JH, You YS, Choe CM, Lee ES. Efficacy of brimonidine tartrate $0.2 \%$ ophthalmic solution in reducing halos after laser in situ keratomileusis. $J$ Cataract Refract Surg. 2008;34:963-967.

20. Edwards JD, Burka JM, Bower KS, Stutzman RD, Sediq DA, Rabin JC. Effect of brimonidine tartrate $0.15 \%$ on night-vision difficulty and contrast testing after refractive surgery. $J$ Cataract Refract Surg. 2008;34: $1538-1541$.

21. Shemesh G, Moisseiev E, Lazar M, Kesler A. Effect of brimonidine tartrate $0.10 \%$ ophthalmic solution on pupil diameter. J Cataract Refract Surg. 2011;37:486-589.

\section{Dovepress}

PubMed Central and CAS, and is the official journal of The Society of Clinical Ophthalmology (SCO). The manuscript management system is completely online and includes a very quick and fair peer-review system, which is all easy to use. Visit http://www.dovepress.com/ testimonials.php to read real quotes from published authors. 